\title{
COVID-19 and Digestive System in Children: A Retrospective Study
}

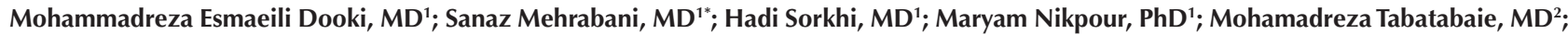 \\ Mohsen Mohammadi, MD ${ }^{1}$; Masood Kiani, MD ${ }^{1}$
}

${ }^{1}$ Non-Communicable Pediatric Disease Research Center, Health Research Institute, Babol University of Medical Sciences, Babol, I.R. Iran ${ }^{2}$ Clinical Research Development Center, Amirkola Children's Hospital, Babol University of Medical Sciences, Babol, I.R. Iran

\begin{abstract}
Background: The aim of this study was to identify gastrointestinal (GI) and liver injury presentations in children admitted with COVID-19 infection.

Methods: In this retrospective study, we studied all children with suspected symptoms of COVID-19, referred to Amirkola Children's Hospital. Clinical manifestations of the digestive and respiratory systems and liver function tests were evaluated for all cases.

Results: Eighteen children were studied. The most common clinical symptoms were fever, anorexia, weakness, nausea and vomiting, cough, diarrhea, and abdominal pain, respectively. Also, 5/18 (27.8\%) and 7/18 (38.9\%) of cases had abnormally high alanine aminotransferase (ALT), aspartate aminotransferase (AST), respectively. Additionally, in icteric cases, direct bilirubin was raised. There was no significant relationship between pulmonary lesions and abnormal excess in ALT $(P=0.59)$ and AST $(P=0.62)$. Conclusion: The findings showed that there were no severe clinical Gl symptoms in children with COVID-19 infection. Besides, children with increased liver enzymes did not have more respiratory involvement than those without a rise in liver enzymes. Keywords: COVID-19, Gastrointestinal tract, Liver, Pediatric

Cite this article as: Esmaeili Dooki M, Mehrabani S, Sorkhi H, Nikpour M, Tabatabaie M, Mohammadi M, et al. COVID-19 and digestive system in children: a retrospective study. Arch Iran Med. 2020;23(11):782-786. doi: 10.34172/aim.2020.104.
\end{abstract}

Received: June 7, 2020, Accepted: September 6, 2020, ePublished: November 1, 2020

\section{Introduction}

Coronaviruses (CoVs) are known as a cause of severe acute respiratory syndrome (SARS-CoV-2) since December 2019 in Wuhan, China. ${ }^{1,2}$ It has become pandemic according to the World Health Organization (WHO) report in March 2020. There have been more than 6,703,686 confirmed cases and more than 393,383 deaths due to the COVID-19 as of June $6 .{ }^{3}$ It seems that children have milder disease than adults. ${ }^{4}$

COVID-19 can damage any vital organs like lung, heart, liver, neurologic system, kidney and gastrointestinal (GI) tract, but mostly causes respiratory and GI symptoms ranging from the common cold to coagulopathy, multiorgan failure and death. ${ }^{1,2}$ The GI symptoms include anorexia, diarrhea, vomiting, nausea, abdominal pain and GI bleeding. A study reported that although diarrhea was the most common GI symptom in children and adults, vomiting was more prominent in children. ${ }^{5,6}$ COVID-19 leads to various degrees of liver injury, presenting with abnormal levels of alanine aminotransferase (ALT), aspartate aminotransferase (AST) and albumin accompanied by slightly elevated bilirubin levels as well as elevated gamma-glutamyltransferase and alkaline phosphatase levels (ALP). ${ }^{7}$ It is proposed that the virus binding to angiotensin-converting enzyme 2 (ACE2) receptors in target cells is the most important mechanism of GI and liver involvement. ${ }^{7,8}$ The highest expression levels of ACE2 receptors are in the small intestine and terminal ileum, while they occur with the lowest frequency in the liver and lungs. ${ }^{8}$ The activity of this receptor is reported to be lower in children than adults. ${ }^{9}$ By isolating the infectious SARS-CoV-2 from the stools of affected patients, it has been proven that this virus can be transmitted through the fecal-oral route. ${ }^{5,10}$

There are few studies regarding GI and liver presentations of COVID-19 in children. The aim of this study was to determine GI and liver injury presentations in children admitted with COVID-19 infection to Amirkola Children's Hospital.

\section{Materials and Methods}

In this retrospective study, the medical records of children with suspected symptoms of COVID-19 were evaluated by two specialists, (Gastroenterologist and health sciences expert). All children were referred to Amirkola children's hospital affiliated to Babol University of Medical Sciences (northern Iran) from March 5 to May20 , 2020. The inclusion criteria included children between two months and 18 years of age, without history of chronic liver, kidney, neuromuscular and congenital heart disease and 
also immune system deficiency. The exclusion criterion was infectious diseases other than COVID-19. Children were defined as having a confirmed or suspected diagnosis of COVID-19 infection based on the Sixth national flowchart and literature articles. ${ }^{11,12}$

\section{Data Collecting}

The RT-PCR test was performed to diagnose SARS-CoV-2 for all children in the Caspian Core Research Laboratory (Amirkola Research Institute).

\section{Evaluation of Clinical and Therapeutic Symptoms}

Clinical manifestations of pediatric study group and all treatment measures (drug and supportive therapies) for children with COVID-19 were also evaluated.

\section{Laboratory Evaluation and Pulmonary Lesions}

To evaluate the digestive system, liver enzymes such as ALT, AST, and ALP, prothrombin (PT), partial thromboplastin time (PTT), international normalized ratio (INR) were measured. Normal cut-off levels for ALT, AST were less than 40 and 35 IU/L for boys and girls, Normal ALP levels were less than $1500 \mathrm{IU} / \mathrm{L}$, albumin was between 3-5.5 g/ $\mathrm{dL}$ and total bilirubin was $0.1-1.2 \mathrm{mg} / \mathrm{dL}$. The direct bilirubin $>20 \%$ total bilirubin $\mathrm{mg} / \mathrm{dL}$ and total bilirubin $>1.2 \mathrm{mg} / \mathrm{dL}$ were considered higher than normal. ${ }^{13}$ In cases with elevated liver enzymes, viral serological markers (A, B, C, D, and E) were measured and assessment for autoimmune hepatitis and Wilson's disease (if necessary) were made, as well.

C-reactive protein (CRP) concentration and erythrocyte sedimentation rate (ESR) were also measured in all children. Normal cut-off levels were $<10 \mathrm{mg} / \mathrm{dL}$ for CRP and $<25 \mathrm{~mm} / \mathrm{h}$ for ESR. ${ }^{14}$ All tests were performed in the laboratory of Amirkola children's hospital. Moreover, stool exam and culture were performed.

Furthermore, high-resolution computed tomography (HRCT) of the lungs and chest radiographs were taken to measure the pulmonary system. On imaging assessment, some features such as ground-glass opacities, unilateral or bilateral nodules and consolidation with the halo sign were examined. All images were evaluated by a pediatric radiologist. Besides, if necessary, ultrasound scan of the liver, spleen and bile ducts was performed.

\section{Statistical Analysis of Data}

The data were analyzed using SPSS 22.0 and descriptive and analytical indicators. $P<0.05$ was considered as significant.

\section{Results}

Patients

Totally, 18 children were recruited to the study. These children with a suspected diagnosis of COVID-19 were admitted to Amirkola children's hospital. Of these 18 children, 13/18 (72.2\%) and 5/18 (27.8\%) cases were identified as confirmed and suspected for COVID-19, respectively.

General and Epidemiology Information

The mean age of children (12 boys and 6 girls) was 6.87 \pm 3.33 years. Among them, 11/18 (61.1\%) were rural and all lived in epidemic regions of COVID-19 infection, and only 3/18 (16.7\%) of them had contact with COVID-19 patients.

\section{Clinical Symptoms and Treatment}

The most common clinical symptoms in children were fever, anorexia, and weakness, respectively (Table 1).

The mean length of hospital stay and the interval between onset of symptoms and admission were $10.29 \pm 4.94$ and $4.41 \pm 2.50$ days, respectively (Table 1 ). About $90 \%$ of

Table 1. Demographic, Epidemiologic and Clinical Characteristics of 18 Children with COVID-19

\begin{tabular}{|c|c|c|}
\hline Variable & Mean & SD \\
\hline Age $(y)$ & 6.87 & 3.33 \\
\hline The length of hospital stay (day) & 10.29 & 4.94 \\
\hline $\begin{array}{l}\text { Interval between symptom onset and admission } \\
\text { (day) }\end{array}$ & 4.41 & 2.50 \\
\hline Variable & $\mathbf{N}$ & $\%$ \\
\hline \multicolumn{3}{|l|}{ Sex } \\
\hline Girl & 6 & 33.3 \\
\hline Boy & 12 & 66.7 \\
\hline \multicolumn{3}{|l|}{ Place of residence } \\
\hline City & 7 & 38.9 \\
\hline Village & 11 & 61.1 \\
\hline \multicolumn{3}{|l|}{ History of chronic underlying diseases } \\
\hline Yes & 3 & 16.7 \\
\hline No & 15 & 83.3 \\
\hline \multicolumn{3}{|l|}{ Fever } \\
\hline Yes & 16 & 88.9 \\
\hline No & 2 & 11.1 \\
\hline \multicolumn{3}{|l|}{ Cough } \\
\hline Yes & 6 & 33.3 \\
\hline No & 12 & 66.7 \\
\hline \multicolumn{3}{|l|}{ Weakness } \\
\hline Yes & 14 & 77.8 \\
\hline No & 4 & 22.2 \\
\hline \multicolumn{3}{|l|}{ Anorexia } \\
\hline Yes & 15 & 83.3 \\
\hline No & 3 & 16.7 \\
\hline \multicolumn{3}{|l|}{ Nausea-Vomiting } \\
\hline Yes & 7 & 38.9 \\
\hline No & 11 & 61.1 \\
\hline \multicolumn{3}{|l|}{ Diarrhea } \\
\hline Yes & 6 & 33.3 \\
\hline No & 12 & 66.7 \\
\hline \multicolumn{3}{|l|}{ Abdominal pain } \\
\hline Yes & 6 & 33.3 \\
\hline No & 12 & 66.7 \\
\hline \multicolumn{3}{|l|}{ Dyspnea } \\
\hline Yes & 5 & 27.8 \\
\hline No & 13 & 72.2 \\
\hline
\end{tabular}


them had oxygen saturation more than 95\%. All cases received antibiotics including ceftriaxone, clindamycin and so on as well as antivirals such as Kaletra. Additionally, if needed, the patients received bronchodilators, Combivent and oxygen support through nasal cannula. All children were discharged with good general condition without morbidity and mortality.

\section{Laboratory Results and Radiography Findings}

The mean values of ALT, AST, prothrombin time (PT), partial thromboplastin time (PTT) and International Normalized Ratio (INR) are presented in Table 2. There was no significant relationship between abnormal excess in ALT $(P=0.38)$ and AST $(P=0.28)$ with confirmed and suspected groups.

Our result showed that on admission, 12/18 (66.2\%) and 14/18 (77.8\%) of cases had elevated ESR and CRP, respectively, which returned to normal levels in $7 / 18$ (38.9\%) and 4/18 (22.2\%) children on discharge. Also, $5 / 18(27.8 \%)$ and $7 / 18(38.9 \%)$ of cases had abnormally high ALT and AST, respectively, which were lowered in $3 / 12(20 \%)$ and $2 / 12(13.3 \%)$ on discharge, respectively. The frequency of abnormal ALP, PT, PTT and INR is presented at Table 2. Albumin was measured in six cases, three of whom had serum albumin levels less than normal. Additionally, in three cases with icteric appearance, total bilirubin (Min: 7.1; Max: 7.6 Mean \pm SD: $7.35 \pm 0.35$ $\mathrm{mg} / \mathrm{dL}$ ) and direct bilirubin levels (Min: 3.4; Max: 4.4 Mean \pm SD: $3.99 \pm 0.70 \mathrm{mg} / \mathrm{dL}$ ) were higher than normal. Viral serology (A, B, C, D and E) and autoimmune hepatitis and Wilson's disease (assessed if needed) were negative in all patients. Furthermore, on admission, 3/18 (16.7\%) of cases had an abnormal stool exam. These cases had elevated red blood cell (RBC) and white blood cell (WBC), in stool smear with negative stool culture, which finally became normal.

The finding of radiography and HRCT examinations suggested that $9 / 18(50.0 \%)$ cases had pulmonary lesions. There was no significant relationship between pulmonary lesions and abnormal excess in ALT $(P=0.59)$ and AST $(P=0.62)$. The findings of ultrasound examination in one case indicated hepatosplenomegaly.

\section{Discussion}

This retrospective study was performed to address GI and liver injury presentations of 18 children admitted with COVID-19 infection. The results illustrated that the most common clinical symptoms of COVID-19 patients were fever, anorexia, weakness, respectively. Furthermore, about a third of them had liver transaminase elevation with mild and transient liver dysfunction.

Although the COVID-19 infection typically presents as a respiratory disease, GI manifestations including diarrhea, vomiting, abdominal pain and liver injury

Table 2. The Mean \pm Standard Deviation and Frequency of Liver Function Test in 18 Children with COVID-19

\begin{tabular}{|c|c|c|c|c|}
\hline \multirow{2}{*}{ Variable } & \multicolumn{2}{|c|}{ Admission to Hospital } & \multicolumn{2}{|c|}{ Discharge from Hospital } \\
\hline & Mean (Min-Max) & SD & Mean (Min-Max) & SD \\
\hline ALT (IU/L ) & $42.61(6-129)$ & 38.74 & 36.16 & 31.65 \\
\hline AST (IU/L ) & $46.07(20-115)$ & 26.52 & 41.33 & 39.03 \\
\hline ALP (IU/L ) & $554.07(264-1181)$ & 233.69 & 371.27 & 142.05 \\
\hline PT (second) & $13.52(12.50-16)$ & 1.17 & $12.65(11.50-13.50)$ & 0.66 \\
\hline PTT (second) & $35.91(27-45)$ & 4.99 & $36.38(27-47)$ & 5.67 \\
\hline \multirow[t]{2}{*}{ INR } & $1.14(1.0-1.50)$ & 0.16 & $1.10(1.0-1.50)$ & 0.15 \\
\hline & $\mathbf{N}$ & $\%$ & $\mathbf{N}$ & $\%$ \\
\hline \multicolumn{5}{|l|}{ ALT (IU/L) } \\
\hline Normal & 13 & 72.2 & 12 & 80 \\
\hline Abnormala $^{a}$ & 5 & 27.8 & 3 & 20 \\
\hline \multicolumn{5}{|l|}{ AST (IU/L ) } \\
\hline Normal & 11 & 61.1 & 13 & 86.7 \\
\hline Abnormal $^{\text {a }}$ & 7 & 38.9 & 2 & 13.3 \\
\hline \multicolumn{5}{|l|}{ ALP (IU/L ) } \\
\hline Normal & 18 & 100 & 11 & 100 \\
\hline Abnormal $^{\mathrm{b}}$ & 0 & 0 & 0 & 0 \\
\hline \multicolumn{5}{|l|}{ PT (Time) } \\
\hline Normal & 8 & 66.7 & 11 & \multirow{2}{*}{100} \\
\hline Abnormal $^{c}$ & 4 & 33.3 & 0 & \\
\hline \multicolumn{5}{|l|}{ PTT (Time) } \\
\hline Normal & 10 & 83.3 & 9 & 81.8 \\
\hline Abnormal $^{d}$ & 2 & 16.7 & 2 & 18.2 \\
\hline \multicolumn{5}{|l|}{ INR } \\
\hline Normal & 10 & 83.3 & 10 & 90.9 \\
\hline Abnormale $^{\mathrm{e}}$ & 2 & 16.7 & 1 & 9.1 \\
\hline
\end{tabular}

${ }^{\mathrm{a}}$ Girl $>35$, Boy $>40 ;{ }^{\mathrm{b}}>1500 ;{ }^{\mathrm{c}}>13.9 ;{ }^{\mathrm{d}}>40.3 ;^{\mathrm{e}}>1.10$. 
may be present. ${ }^{6,7,15} \mathrm{Lu}$ et al reported that diarrhea and vomiting were observed in $8.8 \%$ and $6.4 \%$ in a cohort study of children with the COVID-19 infection. ${ }^{16}$

The exact mechanism of GI involvement in COVID-19 is unknown. The probable mechanism may be first due to the interaction between ACE2 and the COVID-19 virus, as these receptors are abundantly present in small and large intestines. ${ }^{18,19}$ Other possible mechanisms include inflammatory responses such as cytokine storms, drug side effects and finally, the dysregulation of intestinal flora through immune mechanisms. ${ }^{7}$ In 6/18 (33.3\%) cases of our study group with diarrhea, an elevated WBC count was found in 3 stool smear, but all of their stool cultures were negative for bacterial infection. In a study by Wang et al, the results of laboratory fecal test demonstrated that $6.9 \%$ of patients had fecal abnormalities. ${ }^{5}$

Mildly elevated liver transaminase levels [5/18 (27.8\%) and 7/18 (38.9\%) for ALT and AST, respectively], were seen in our patients. A mild transaminase elevation is common in COVID-19 but serious liver dysfunction is not usual. ${ }^{15}$ The incidence of liver injury is $14.8 \%-78 \%$, mostly manifesting with abnormal levels of ALT and AST as well as mildly elevated bilirubin levels. ${ }^{7}$

In a study on COVID-19 in children, ALT and AST were elevated in only $6 \%$ and $9 \%$ of 36 patients, respectively. ${ }^{14}$ In contrast, Cai et al ${ }^{20}$ conducted a study on 417 adults with COVID-19 and concluded that $23.4 \%$ and $14.8 \%$ patients had elevated ALT and AST levels $>3 \times$ the upper limit of normal, respectively. The reason for this difference can be that the manifestations of COVID-19 are different in different parts of the world. COVID-19 in our regional study group was mostly associated with GI complications. Transient liver dysfunction with mild elevation of PT and low albumin levels in a small study group as well as increased total and direct bilirubin in icteric patients were observed, while normal levels were achieved at the time of discharge from hospital

Liver injury may occur due to the cytopathic effects of the virus, binding to ACE2 receptors in hepatocytes and especially, cholangiocytes and immune-mediated inflammation. Another possible factor may be the high positive end-expiratory pressure level that can cause hepatic congestion by increasing right atrial pressure. Indeed, drug-induced liver injury caused by COVID-19 treatment should be carefully considered.7,15

Moreover, total and direct bilirubin levels were higher than normal in cases with icteric appearance. Bilirubin levels are also more than double in those with severe infection compared to those with milder disease. ${ }^{15}$

The limitations of the study were as follows: First, it was a retrospective study and the data were extracted from medical records. Second, the sample size was small. Hence, our study is a preliminary study and further studies are needed with larger samples of pediatric patients with GI and liver diseases to better define the characteristics of this virus in children.

In conclusion, our study findings suggest that in children without underlying diseases and with COVID-19, there are no severe clinical GI symptoms. In addition, children with increased liver enzymes and bilirubin did not have more respiratory symptoms than those without elevated liver enzymes.

\section{Authors' Contribution}

All authors contributed to the study conception and design. Material preparation, data collection and analysis were performed by SM, MED and MN. The first draft of the manuscript was written SM and MN and MED and HS commented on previous versions of the manuscript. All authors read and approved the final manuscript.

\section{Conflict of Interest Disclosures}

We declare no competing interests.

\section{Ethical Statement}

This study was approved by the Ethics Committee of Babol University of Medical Sciences with the code ID: IR.MUBABOL. REC.1399.184.

\section{Acknowledgements}

We would like to thank all nurses of Amirkola hospital, Babol, Iran, who care for the children with COVID-19. Also, we are grateful to the Clinical Research Development Committee of Amirkola children's hospital, Health Research Institute of Babol University of Medical Sciences for their support and cooperation with the study.

\section{References}

1. Qiu H, Wu J, Hong L, Luo Y, Song Q, Chen D. Clinical and epidemiological features of 36 children with coronavirus disease 2019 (COVID-19) in Zhejiang, China: an observational cohort study. Lancet Infect Dis. 2020;20(6):689-96. doi: 10.1016/S1473-3099(20)30198-5.

2. Zimmermann $\mathrm{P}$, Curtis N. Coronavirus Infections in children including COVID-19: An overview of the epidemiology, clinical features, diagnosis, treatment and prevention options in children. Pediatr Infect Dis J. 2020;39(5):355-368. doi: 10.1097/INF.0000000000002660.

3. Coronavirus disease (COVID-19) pandemic. Available from: https://www.who.int/emergencies/diseases/novel-coronavirus-2019?gclid=EAlalQobChMluZGM-ojE6QIVHMayCh1TMgKdEAAYASAAEgIDDvD_BwE.

4. Ludvigsson JF. Systematic review of COVID-19 in children show milder cases and a better prognosis than adults. Acta Paediatr. 2020;109(6):1088-1095. doi: 10.1111/apa.15270.

5. Tian Y, Rong L, Nian W, He Y. Gastrointestinal features in COVID-19 and the possibility of faecal transmission. Aliment Pharmacol Ther. 2020;51(9):843-851. doi: 10.1111/ apt.15731.

6. Wong SH, Lui RN, Sung JJ. Covid-19 and the digestive system. J Gastroenterol Hepatol. 2020;35(5):744-748. doi: 10.1111/ jgh.15047. Epub 2020 Apr 19

7. Musa S. Hepatic and gastrointestinal involvement in coronavirus disease 2019 (COVID-19): What do we know till now? Arab J Gastroenterol. 2020;21(1):3-8. doi: 10.1016/j. ajg.2020.03.002.

8. Pirola CJ, Sookoian S. COVID-19 and ACE2 in the liver and gastrointestinal tract: Putative biological explanations of sexual dimorphism. Gastroenterology. 2020:S0016-5085(20)305692. doi: 10.1053/j.gastro.2020.04.050.

9. Dong Y, Mo X, Hu Y, Qi X, Jiang F, Jiang Z, et al. Epidemiological characteristics of 2143 pediatric patients with 2019 coronavirus disease in China. Pediatrics. 2020; 58(4):712-3. 
doi: doi: 10.1542/peds.2020-0702.

10. Zhang T, Cui X, Zhao X, Wang J, Zheng J, Zheng G, et al. Detectable SARS-CoV-2 viral RNA in feces of three children during recovery period of COVID-19 pneumonia. J Med Virol. 2020;92(7):909-914. doi: 10.1002/jmv.25795.

11. Ai T, Yang Z, Hou H, Zhan C, Chen C, Lv W, et al. Correlation of chest CT and RT-PCR Testing for coronavirus disease 2019 (COVID-19) in China: A Report of 1014 Cases. Radiology. 2020;296(2):E32-E40. doi: 10.1148/radiol.2020200642.

12. Available from: URL: https://corona.ir/media/upload/1399/02/ tshkhyswdrmankwwyd19-5eaf1816c15d0.pdf.

13. Kleinman RE, Goulet OJ, Mieli-Vergani G, Sanderson IR, Sherman PM, Shneider BL. Walker's Pediatric Gastrointestinal Disease: Physiology, Diagnosis, Management. 6th ed. USA Raleigh, North Carolina: People's Medical Publishing House Co., Ltd; 2018:1176-9

14. Kiani M, Mohammadpour-Mir A, Sorkhi H, Esmaeili-dooki M, Nikpour M, Babazadeh K, Tabatabaie M. Multi organ presentation of children with COVID-19 infection in north of Iran: a retrospective study. International Journal of Pediatrics. 2020; In Press.

15. Matthai J, Shanmugam N, Sobhan P; Indian Society of Pediatric
Gastroenterology, Hepatology and Nutrition; Pediatric Gastroenterology Chapter Of Indian Academy Of Pediatrics. Coronavirus Disease (COVID-19) and the Gastrointestinal System in Children. Indian Pediatr. 2020:S097475591600162.

16. Lu X, Zhang L, Du H, Zhang J, Li YY, Qu J, et al. SARS-CoV-2 Infection in Children. N Engl J Med. 2020;382(17):1663-1665. doi: 10.1056/NEJMc2005073.

17. Wang S, Guo L, Chen L, Liu W, Cao Y, Zhang J, Feng L. A Case Report of Neonatal 2019 Coronavirus Disease in China. Clin Infect Dis. 2020;71(15):853-857. doi: 10.1093/cid/ciaa225

18. Xiao $F$, Tang $M$, Zheng $X$, Liu $Y$, Li $X$, Shan $H$. Evidence for Gastrointestinal Infection of SARS-CoV-2. Gastroenterology. 2020;158(6):1831-1833.e3. doi: 10.1053/j. gastro.2020.02.055.

19. Harmer D, Gilbert M, Borman R, Clark KL. Quantitative mRNA expression profiling of ACE 2, a novel homologue of angiotensin converting enzyme. FEBS Lett. 2002;532(12):107-10. doi: 10.1016/s0014-5793(02)03640-2.

20. Cai Q, Huang D, Yu H, Zhu Z, Xia Z, Su Y, et al. COVID-19: Abnormal liver function tests. J Hepatol. 2020;73(3):566-574. doi: 10.1016/j.jhep.2020.04.006. 